minorities in the United States, but the Late Sensatewhich is even more dislikable-is not yet upon us and may yet be avoided. All this may strike a clear bell with those who consider that contemporary social problems are all reducible to variations on the tale of what happened to Lot's wife, but it is impossibly schoolboyish as a description of the character of social change. Although they claim the support of "most philosophers of history" for their belief that signs of what they call Sensate in, say, art are also evidence of the emergence of Sensate tendencies elsewhere in society, their application of the principle is foolish. The truth is that there is no evidence to suggest that the evolution of societies is a linear process, that societies at any time can be described by a single adjective, or that the kinds of historical conditions of which the world already has experience are likely to exhaust the range of historical possibilities. In brief, Drs Kahn and Wiener, who let their imaginations run riot on science and technology, are curiously leaden when it comes to history. The kinds of futures which they foresee are almost entirely determined by recent political experience in the United States. That this should be so is not surprising, but it does mean that the book, huge though it is, is not so much a framework for speculation as a tightrope.

When it comes to suggesting what kinds of technical possibilities may be opened up in the three remaining decades of this century, Drs Kahn and Wiener are imaginative enough but lacking in judgment or at least the appearance of judgment. One of the most tangible parts of their book is a list-another list"One hundred technical innovations very likely in the last third of the twentieth century". This is a brave enterprise but one which is largely meaningless. What, for example, is to be made of the item "new and useful plant and animal species" fairly high on the list, among the near certainties? It is natural to ask whether the authors are thinking of new varieties, such as the strains of wheat and rice which seem to have brought joy to farmers in India and Pakistan in recent months. If, however, they are really thinking of new species, it is surely their duty to be a little more explicit. Unfortunately a good deal of their list is ambiguous in the same way, somehow straddled between platitude and outrage. To be sure, on one reading, Drs Kahn and Wiener are merely following the fortune-tellers and hedging their bets, but the process diminishes their credibility. The real trouble, however, is that Drs Kahn and Wiener seem not to appreciate as clearly as they should the practical distinction between innovation and change. Even very recent history, however, shows clearly enough that even the important technical revolutions may be slow to have a practical effect. The speed with which atomic power stations will come into service is probably determined as closely by the availability of capital as by technical considerations. By the same test, the rate at which new devices such as lasers are likely to influence the pattern of telecommunications will be determined by the speed with which existing networks, already huge, can be extended and renewed. In other words, in technological prophecy, the real interest is to know what will happen and not what might happen.

\section{Canadian Science Policy}

Is Canada a developing country? Dr O. M. Solandt, Chairman of the Science Council of Canada, thinks it is. When he gave the third Science of Science Foundation Lecture at the Royal Institution on April 23, he suggested that Canada's experience was an unusual combination, sharing the characteristics of highly developed economies and the large under-exploited regions more typical of underdeveloped countries. For this reason, he was hopeful that Canada's experience in trying to put science to work would be valuable both to the mature nations of Europe and to the developing nations of Asia and Africa.

Most nations, Dr Solandt said, have neither explicit goals nor a mechanism for formulating them. Scientists had a duty to point this out, although it would be presumptuous for scientists to try to formulate the goals - science is by no means the only important activity in the nation. Those who were responsible for trying to recommend science policies would have to establish hypothetical goals as a basis for policy. One of Canada's aims, he implied, was that of shifting expenditure away from the government laboratories, and towards universities and industry instead. This process had now been going on for some years and was of considerable importance.

He explained that the Canadian Science Council, the body charged with advising the Government on science policy, had no operating or budget responsibilities to interfere with its objectivity. One of its recommendations had been that a Canadian Space Agency should be set up to co-ordinate and plan Canadian space programmes. Unfortunately, it had proved impossible to implement the recommendation, because there was no effective body in the Government to convert the policy recommendation into action. Each of the agencies concerned with space activities already had its own vested interests. In the event, Dr Solandt said, an ad hoc group in the cabinet secretariat had been set up to deal with the problem. As a more permanent solution to these problems, Dr Solandt suggested the formation of a Ministry of Science with no responsibility for operations, which could deal both with the formation of policy and its conversion into reality.

\section{Jaguar Unveiled}

ON April 17 the strike/trainer aircraft Jaguar was rolled out from the Breguet works in Velizy-Villacoublay. After the dismal experiences of the past few years, when cancellations have come thick and fast, it is very hard to see how the Anglo-French Jaguar has survived. But it has, and now seems set to go into production, with orders for 200 from the Royal Air Force and a similar number from the French Air Force. No doubt the comparatively modest cost of the aircraft (although each will cost $£ 620,000$, the F111 would have been four times as much), the hope of export orders, and the fact that it is a collaborative project have all helped to keep the Jaguar in business. But these are hardly compelling strategic arguments. Without the F111 or the Anglo-French variable geometry aircraft (both cancelled by the British 
Government under financial pressure), the need for an advanced trainer, which is what the Jaguar is, is very far from obvious.

Of course, like most aircraft these days, the Jaguar is expected to do more than simply train pilots to fly at Mach 1.7. The aircraft has five roles: as an advanced trainer for the French and British air forces, as a tactical support aircraft by both air forces, and as a tactical aircraft for the French Navy. As a tactical aircraft, Jaguar can carry a variety of systems-air to air

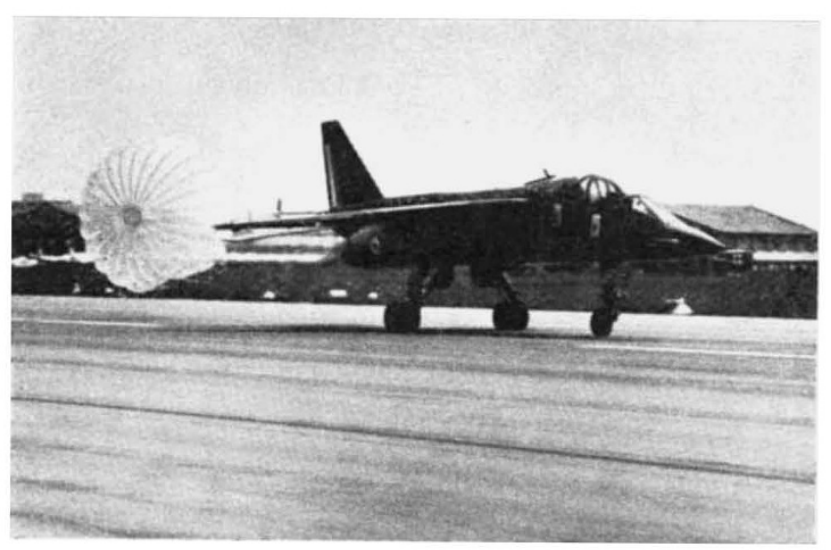

missiles, 1,000 lb bombs, rocket launchers and Martel missiles, though not all at once. The British Ministry of Defence originally stated that the Jaguar would be used to enable Phantoms to be released to replace obsolete Lightnings. In this sense, it is a secondary strike system, cheap to buy, easy to fly, with the capacity to take off from short, ill-prepared runways and with a good range. It is small, about the same size as the Hawker Hunter, has a radius of action of 320 nautical miles, and can be flown for 2,430 nautical miles if external fuel tanks are fitted. The aircraft has two engines, built jointly by Rolls-Royce and Turbomeca, and called the RB 172 T260 Adour.

So far, this sounds like a blueprint for a replacement for the Hawker Hunter in air forces like those of Jordan. And it is clear that the makers of the aircraft are hoping for substantial export orders - they hope 1,000 Jaguars can be sold. If they are not, the project can hardly be justified. Although the aireraft has some room for development, it is never likely to amount to an effective substitute for the cancelled variable geometry aircraft. $£ 124$ million is a lot to pay for a squadron or two of relatively unsophisticated aeroplanes-even in the training function, the Jaguar will not be the complete answer. The Ministry of Defence also intends to produce a training version of the Harrier, another small aircraft which at least has vertical take-off to recommend it. But there are signs that an export market exists - a fairly well substantiated story suggests that Japan is in the market for the Adour engine, to power its own training aircraft, the TX. This will please Rolls-Royce, although the British Aircraft Corporation would doubtless prefer to sell the entire aircraft.

\section{Reflexions on Todd}

Enthusiasm tinged with fear seems to be the general reaction to the Todd report on medical education (see
Nature, 218, 121; 1968). Enthusiasm for a majority of the proposals is dampened by the fear that the report will be pigeonholed and no action taken. Developments now in the pipeline but not in line with the report would therefore be dropped with nothing else put in their place. As it is, changes like a reorganization of curricula have been hanging around waiting for the recommendations. Building plans in various stages of completion are also affected.

Expansion of medical training is obviously necessary. The recommendations for the form that the training should take seem to have received widespread approval. Pre-clinical teachers are welcoming the idea of a medical degree, although the cost of providing enough laboratory accommodation is likely to be a drawback. Vocational training for general practitioners as described in the report includes much that has already been called for by the College of General Practitioners. Although some critics say that, with the current shortage of general practitioners, this is no moment to raise the standards, there is a feeling that unless something is done in this direction people will not be attracted into general practice at all and the shortage will become more serious. Recommendations for reorganization of the curriculum are welcomed, although there are doubts about the availability of staff and money which would be necessary. Contributions by the students would help this problem, and it has been suggested that this would be a good moment to review the whole question of student financing, both in medicine and other subjects.

A large section of the report deals with the hospitals and medical schools in London. It has been recognized for some time that some sort of rationalization is necessary, and the proposed links of teaching hospitals with university colleges are welcomed. On the other hand, there is a feeling that the postgraduate hospitals might lose their identity if grafted on to the new double undergraduate hospitals. The report suggests rather than makes definite recommendations about how the various institutes and postgraduate hospitals might join up, but it seems likely that even the suggestions will not be too kindly received. The Institute of Neurology and the National Hospital in Queen Square, for example, are already involved with plans for rebuilding on the present site, and they see no reason to move to join the Guy's/King's College group when they are so close to various libraries and particularly to University College, where basic neurological research is carried out. It has been murmured that the commission, in its attempts at rationalization, ended up playing jigsaws, fitting in the postgraduate hospitals to make a tidy picture rather than for positive reasons. And the Hammersmith hospital, which has its own particular brand of postgraduate school staffed entirely by full-time university staff, has been left with no undergraduate link, although such links are an important feature of the report.

\section{IBP General Assembly}

The International Biological Programme (IBP) is very nearly a year into the active phase of its five-year lifetime, but already there are worries about what is to happen to uncompleted projects when the programme ends in 1972. There are likely to be quite a number. Most of the American and Soviet IBP projects, for 